\title{
APPLYING THE REPERTORY GRID METHOD FOR TECHNOLOGY FORECASTING: CIVIL UNMANNED AVIATION SYSTEMS FOR GERMANY
}

\author{
Jörgen Eimecke ${ }^{1}$, Katrin Baumert ${ }^{2}$, Daniel Baier ${ }^{1}$ \\ 1 University of Bayreuth, Chair of Innovation and Dialogue Marketing, Germany \\ ${ }^{2}$ Brandenburg University of Technology Cottbus-Senftenberg, Chair of Planning and Innovation Management, \\ Germany
}

Corresponding author:

Jörgen Eimecke

University of Bayreuth

Chair of Innovation and Dialogue Marketing

Universitätsstraße 30, 95447 Bayreuth, Germany

phone: (+49) 921554343

e-mail: joergen.eimecke@uni-bayreuth.de

Received: 30 September 2016

Accepted: 5 April 2017

\begin{abstract}
Multistage expert surveys like the Delphi method are proven concepts for technology forecasting that enable the prediction of content-related and temporal development in fields of innovation (e.g., [1, 2]). Advantages of these qualitative multistage methods are a simple and easy to understand concept while still delivering valid results [3]. Nevertheless, the literature also points out certain disadvantages especially in large-scale technology forecasts in particularly abstract fields of innovation [4]. The proposed approach highlights the usefulness of the repertory grid method as an alternative for technology forecasting and as a first step for preference measurement. The basic approach from Baier and Kohler [5] is modified in-so-far that an online survey reduces the cognitive burden for the experts and simplifies the data collection process. Advantages over alternative approaches through its simple structure and through combining qualitative and quantitative methods are shown and an adaption on an actual field of innovation - civil drones in Germany - is done. The measurement of a common terminology for all experts minimizes misunderstandings during the interview and the achievement of an inter-individual comparable level of abstraction is forced by the laddering technique [6] during the interview.
\end{abstract}

KEYWORDS

civil drones, innovative product development, multistage expert surveys, quality requirements, qualitative research, quantitative research, repertory grid method, technology forecasting.

\section{Introduction}

For innovative product development, it is of particular importance that an early design specification meets the requirements of customers (e.g., [7]). The subjective evaluation by preference measurement of alternatives is a popular way to specify a new product design (e.g., [8]).

Nevertheless, before preferences can be measured the possible specifications have to be identified. The customer's point of view about what is really relevant has to be analyzed (e.g., [9]). In innovation fields, methods of technology forecasting are used to capture expert knowledge before real customer needs are available. Since many years multistage expert surveys like the Delphi method are proven concepts for technology forecasting. Using them enables the prediction of content-related and temporal development in innovation fields (e.g., $[1,2])$.

These qualitative multistage methods - contrary to other predicting methods - deliver valid results and are simple and easy to understand [3]. Low costs and low expenditure of time are further advantages as well as the integration of the knowledge of a va- 
riety of experts in a structured way (e.g., [10, 11]). Nevertheless, the literature also points out certain disadvantages (e.g., $[2,11,12])$. Especially in largescale technology forecasts in particularly - abstract fields of innovation - the development in a standardized way is needed [4]. However, the individual judgment structures of the experts also have to be represented and explicitly formulated. Therefore, the performance of the Delphi method is restricted ([11, 12]). Baier and Kohler [5] proposed the repertory grid method as an alternative by combining qualitative and quantitative methods. In this investigation, this method is adapted and adjusted by online surveying on an actual field of innovation, the requirements for civil drones in Germany.

The paper is structured as follows: The underlying repertory grid method is reflected in the next chapter. The further development, the adaption of the approach by Baier and Kohler [5] and the survey instruments are described in a third chapter. Then, the data collection steps for the application are summarized. The innovation field under investigation are civil unmanned aviation systems (so called drones) in Germany. The paper ends with results and a description of advantages and disadvantages of the used approach as well as some conclusions.

\section{The repertory grid method}

In the context of his theory of personal constructs George A. Kelly developed in the 1950s the repertory grid method [13]. He pointed out the assumption that each human individual constructs his own reality and thus forms a specific construct system that can be used for the evaluation elements of self, the environment or for evaluation of relations with others. The construct systems relate to real objects (for example, people, situations, problems or possible solutions) and are influenced by events and experiences. Based on these real objects he or she forms dichotomous distinctions (construct versus contrast like pole and antipole). The distinctions can subsequently be used to classify and evaluate new objects [14].

Kelly [13] developed the so-called role construct repertory grid to use the individual construct systems in psychotherapy. The general accessibility and use of the instrument in non-clinical studies ensured that this method was known as 'repertory grid technique' $[15,16]$. Usually this method is applied in situations with concrete objects. The aim is the determination of the individual construct system, which is designed to differentiate between known and partly new objects.
A series of dichotomous discrimination tasks are the basis of the repertory grid method. The subject has to divide a predetermined number of elements a subsample of the objects under investigation - into two non-empty groups. On the one hand there is the possibility that constructs could be determined by a dyad comparison, on the other hand triads can be chosen as a basis for comparison. In generally it is assumed that the triad method is the preferable approach for construct determination (cf. [17, 18]), thus Baier and Kohler [5] have also chosen this approach.

The advantage of the triad comparison is the fact that in this case both a similarity and a difference discrimination is necessary. Thereby, the constructs and features are getting more versatile and cognitively complex [19].

In view of the foregoing Baier and Kohler [5] suggested the repertory grid method as an alternative of using the Delphi method. Their approach also consists of a multi-stage expert survey but also links superior qualitative interviews with a quantitative evaluation approach. Using the example of mobile information and communication technology for cars they have been able to point out the advantages of this approach: The investigated innovation field is not structured by the operatives of the interviews, but by the expert subjects.

Because of the open interview situation in the repertory grid method advantages are resulting for detecting different individual thoughts (expressed in so-called construct systems that will be explained later). The subsequent aggregation of construct systems provides a meaningful look into the future.

In this contribution a renewed use of this methodology and a recent application example are discussed. The new application example is an innovation field - 'civil unmanned aviation systems less than $25 \mathrm{~kg}$ take-off weight' (civil micro-drones).

\section{Technology forecast by using the repertory grid method}

The repertory grid method can be used for various purposes. Baier and Kohler [5] proposed to use this methodology for technology forecasting. The central component is a first round of questioning, with the objective to systematically collect particularly important examples, similarities, differences and characteristics of alternatives in an innovation field and to try to structure them in the language of technical experts. In a (optional) second round the effectiveness of success of single characteristics is analyzed in order to determine the chances of success of possible alternatives. 


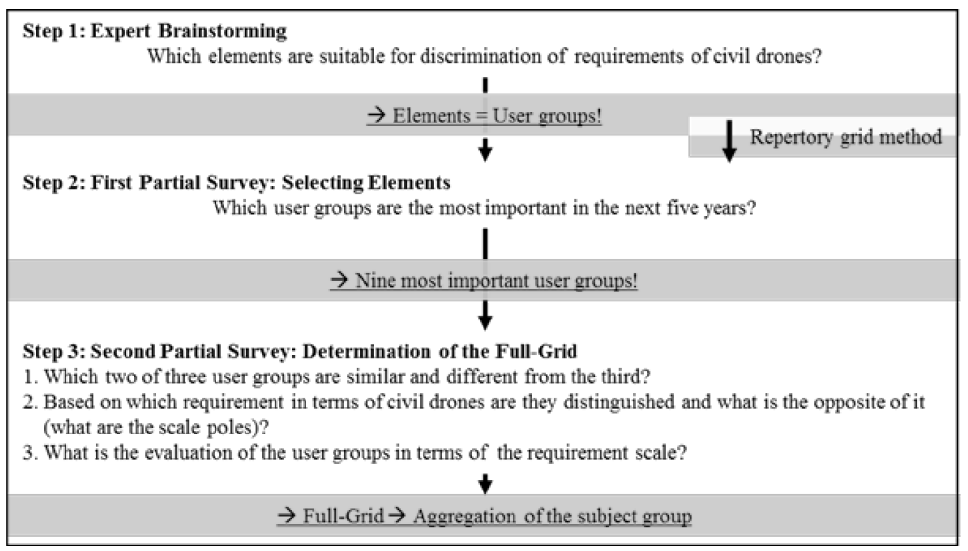

Fig. 1. Survey sequence.

The first round of questioning includes three steps: element collection, construct surveying by triad comparison and evaluation of elements in the socalled Full-Grid. By the quantitative evaluation in the last step effectiveness of success of individual constructs for each element and thus their chances of success are often already very concretely visible. A separate review at a second expert survey can therefore be dropped. These three steps are explained below using the example of a new application in an innovation field.

The presented application concerns the innovation field of 'civil unmanned aviation systems less than $25 \mathrm{~kg}$ take-off weight'. For this innovative field it is expected - as part of a technology forecasting - to clarify with subject matter experts, which user groups or rather application industries in a time horizon of five years would be the most important and which different requirements apply on the technology of these applications. In the still largely unregulated innovation field of civil drones the resulting findings have great importance for both manufacturers and government.

Figure 1 shows the sequence of the expert survey. It includes - as already mentioned - the usual three steps of using the repertory grid method (see, e.g., $[20,21])$. The result is the so-called Full-Grid, representing an aggregated and individually valued construct system. In the presented approach - unlike to Baier and Kohler [5] - these three steps were distributed to a brainstorming with experts and two partial expert surveys with the objective of lower time burden and lower cognitive load for the subjects. So for selecting elements (here user groups) a brainstorming with experts was performed (step 1). Both partial surveys (steps 2 and 3 ) were conducted by telephone interviews. In step 3 - following the principle of a preferably simple consultation (see, e.g., [22]) - a visualization via online questionnaire was used to again minimize the cognitive load of the subjects and the time required for the survey in a telephone interview.

\section{Expert brainstorming and first partial survey: selecting elements}

The brainstorming in the first step and the first partial survey in the second step had to select the target user groups as specific elements for distinguishing requirements of civil drones. First, the innovation field was pre-structured with four experts as part of a brainstorming session and user groups have been chosen as elements.

The technological and regulatory development of civil drones is still at an early stage and very complex. Besides proper unmanned aircraft (the drone), the object of investigation is enhanced to an unmanned system with wireless communication, ground station (in the simplest case a remote control) and human resources (at least one pilot) and their qualification.

On the one hand the flight characteristics of the drone are relevant to different requirements in different applications; an overview procurement by imaging sensors has, for example, completely different requirements in case for the police than for private users.

At the other hand important criteria are the usability and the variety of functions of the remote control - for example there should be redundancy for safety-critical applications - and also the payload of the drone. In addition to the pure transport almost any imaginable sensor (from simple camera to 'sniffing sensors' for detecting gases) could be connect to the drone. Different requirements for standardization, resilience or training and aspects of autonomous flying or of data protection and data security incre- 
Management and Production Engineering Review

Table 1

User groups of civil drones, selection, description, frequency.

\begin{tabular}{|c|c|c|c|}
\hline Ser. no. & User group (description) & Frequency & $\%$ of mentions \\
\hline 1 & $\begin{array}{c}\text { (Construction) Industry Services and Surveying } \\
\text { (e.g., progress monitoring or mapping) }\end{array}$ & 9 & $17 \%$ \\
\hline 2 & $\begin{array}{c}\text { Agriculture and Forestry } \\
\text { (e.g., precision agriculture, quantification of stocks) }\end{array}$ & 9 & $33 \%$ \\
\hline 3 & $\begin{array}{c}\text { Marketing and Media } \\
\text { (e.g., agency or studios for e.g. advertising or documentaries) }\end{array}$ & 7 & $46 \%$ \\
\hline 4 & $\begin{array}{c}\text { Internal Security } \\
\text { (e.g., (federal) police for e.g. monitoring of major events) }\end{array}$ & 5 & $56 \%$ \\
\hline 5 & $\begin{array}{l}\text { Fire and Disaster Protection } \\
\text { (e.g., firefighting, flood protection) }\end{array}$ & 5 & $65 \%$ \\
\hline 6 & $\begin{array}{c}\text { Security Services } \\
\text { (e.g., private security for monitoring of industrial areas) }\end{array}$ & 4 & $72 \%$ \\
\hline 7 & Private Users (e.g., modeler, hobbyists, private photographs) & 3 & $78 \%$ \\
\hline 8 & $\begin{array}{c}\text { Energy Producers and Critical Infrastructure } \\
\text { (e.g., railway or inspections) }\end{array}$ & 3 & $83 \%$ \\
\hline 9 & Logistics and Transport (e.g., delivery services) & 3 & $89 \%$ \\
\hline Further six mentions & Research, Zoology, Environmental Protection ... & 6 & $100 \%$ \\
\hline \multicolumn{2}{|c|}{ Total mentions of all six experts: } & 54 & \\
\hline
\end{tabular}

ase the complexity of the innovation field and further complicate a differentiated view based on simple elements such as drone applications.

Because of this high complexity in the first step the expert brainstorming - a differentiation according to various user groups of civil drones (in which a drone application have to meet different requirements) was chosen.

Subsequently six other experts participated to the first partial survey to choose the most important nine user groups in a time horizon of five years. The experts were asked to thoroughly describe the selected user groups by examples of applications for civil drones. This description was for a common understanding within the second expert survey of high importance.

The $6 \times 9=54$ particulars of the six experts were then aggregated. The nine most often mentioned user groups could be determined (see Table 1, frequencies over six result from the aggregation).

The mentioned user groups (elements) represent examples of alternatives in the innovation field. Within the second expert survey constructs were determined which reflect the specific similarities and differences. Following the recommendation of [16] nine elements per person were selected and nine triad comparisons were provided (see, [5]).

\section{Second partial survey: determination of the full-grid}

The triad comparison is the central area of the open-ended construct collection of the repertory grid method. The subjects have to decide which two of three given elements, are similar and different from the third element. This option includes a property to distinguish; it must be designated by the subject by a reference to two poles (for example, complex and simple) and forms the determined 'construct'. The first mentioned constructs of the subjects are usually not explicit and are further specified by applying the laddering technique by the interviewer. The laddering technique is a special questionnaire technique for in-depth interviews. By using so-called Why- and How-questions higher- or lower-lying levels of constructs could be determined (cf. [6]).

The two poles are used to evaluate each element (user group). The evaluations of all elements together form the so-called Full-Grid per subject on an individual level. By the following aggregation of the constructs an interpersonal Full-Grid is produced, which includes an expert overarching construct system (see $[20,21])$.

For the second partial survey a total of 16 experts were interviewed in telephone interviews, supported by a visualized online questionnaire. The renowned experts were carefully chosen from the fields of research, development (manufacturer), sales, distribution (middlemen), networking (networks of providers) and government agencies (for example, national aviation authorities), service providers and end users. Thus, requirements of various end users from industry, private use and authorities could be integrated into the results. The high diversity of participants plays an important role and is documented in several studies on technology forecasts (see, e.g., [10]). The interview time varied between 30 and 
50 minutes and could be reduced by the previous sending of supportive online questionnaires (objective and process were known by the subjects at the beginning of telephone interviews).

The construct determination included nine triad comparisons of the nine elements (combinations: 1-2-3, 4-5-6, 7-8-9, 1-4-7, 2-5-8, 3-6-9, 1-5-9, 2-6-7 and 3-4-8) and the subsequent evaluation of the elements with respect to the constructs. The aim was to raise the various requirements for civil drones in the various user groups. Exemplary of the triad comparison and final evaluation of an element is shown in Fig. 2.

In this example, the respondent chose out of the element triad '(Construction) Industry and Surveying', 'Marketing and Media' and 'Internal Security' the first two elements as similar. He named as a distinguishing criterion the construct poles 'High resolution' and 'Low resolution'. After the triad comparison he evaluated the elements (user groups) on a scale with seven levels, where ' 1 ' fully corresponds to construct pole 'High resolution' and '7' fully corresponds to construct antipole 'Low resolution'.

The evaluation of the elements with respect to the constructs in a matrix like the one Baier and Kohler did in 2002 was rejected after a pretest and replaced by an element-wise evaluation of all constructs. Likewise, the possibility of a pure online survey was discarded. In both discarded variants in the pretest the subjects assessed the task as too complex.

The survey subsequent aggregation of the constructs and the corresponding evaluations provides statements on the requirements for civil drones each user group on an overindividual level. The 144 constructs named by 16 experts were aggregated to 24 construct classes. For 20 single nominations, no parent construct class could be assigned. The ten most common construct classes were used for further analysis; they comprise $58 \%$ of all named constructs (see Table 2).

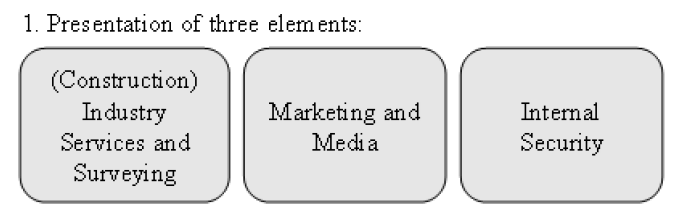

2. Selection of two similar elements
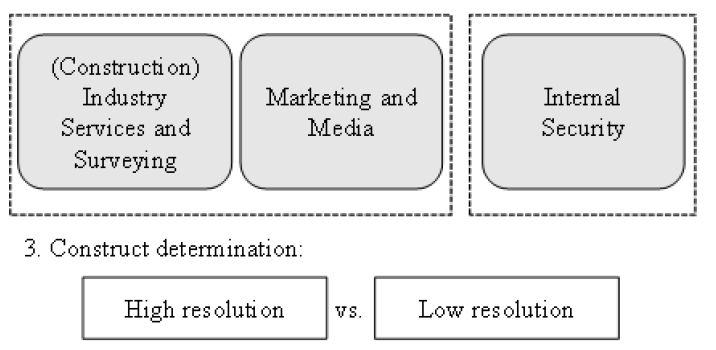

4. Evaluation of all nine elements for each construct:

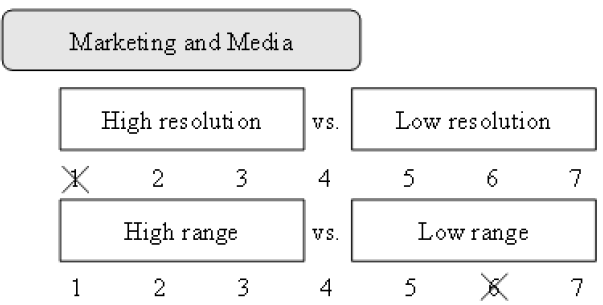

Fig. 2. Triad comparison, construct determination, evaluation.

Table 2

Frequency analysis of construct classes.

\begin{tabular}{|c|c|c|c|c|}
\hline \multirow{2}{*}{ Seq. no. } & \multicolumn{2}{|c|}{ Construct classes } & \multirow{2}{*}{ Frequency } & \multirow{2}{*}{$\%$ of mentions } \\
\hline & Pole & Antipole & & \\
\hline 1 & Special sensors & Only optical sensors & 13 & $9 \%$ \\
\hline 2 & High autonomy & Low autonomy & 11 & $17 \%$ \\
\hline 3 & High resolution & Low resolution & 10 & $24 \%$ \\
\hline 4 & High flight time & Low flight time & 9 & $30 \%$ \\
\hline 5 & High safety requirements & Low safety requirements & 8 & $35 \%$ \\
\hline 6 & High professionalism of the devices & Low professionalism of the devices & 8 & $41 \%$ \\
\hline 7 & High range & Low range & 7 & $46 \%$ \\
\hline 8 & Subsequent data processing & Instant live data processing & 7 & $51 \%$ \\
\hline 9 & High robustness & Low robustness & 6 & $55 \%$ \\
\hline 10 & High reliability & Low reliability & 5 & $58 \%$ \\
\hline $\begin{array}{c}\text { Further } 14 \\
\text { construct classes }\end{array}$ & \multicolumn{2}{|c|}{$\begin{array}{l}\text { Data transmission, payload, commerciality, data protection, } \\
\text { raining, availability, flexible payload, price, detectability, usability... }\end{array}$} & 40 & $86 \%$ \\
\hline Further 20 mentions & \multicolumn{2}{|c|}{$\begin{array}{l}\text { Noise pollution, handover functionality, situational routing, } \\
\text { effort of data analysis, effort of flight planning, indoor, ... }\end{array}$} & 20 & $100 \%$ \\
\hline \multicolumn{3}{|c|}{ Total construct classes over 16 interviews: } & 144 & \\
\hline
\end{tabular}


Table 3

Extract of the aggregated full-grid.

\begin{tabular}{|c|c|c|c|c|c|c|c|c|c|c|c|}
\hline & Elements & 1 & 2 & 3 & 4 & 5 & 6 & 7 & 8 & 9 & \\
\hline & $\begin{array}{l}\text { Rating "1" } \\
\text { (pole) }\end{array}$ & 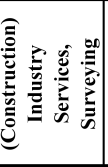 & 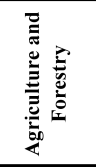 & 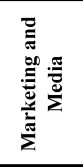 & 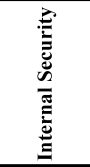 & 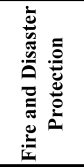 & 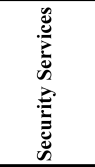 & 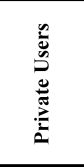 & 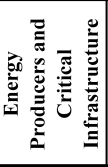 & 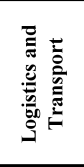 & $\begin{array}{l}\text { Rating "7" } \\
\text { (antipol) }\end{array}$ \\
\hline 1 & Special sensors & $\begin{array}{c}2,923 \\
(1,115)\end{array}$ & $\begin{array}{c}3,385 \\
(1,660)\end{array}$ & $\begin{array}{c}6,769 \\
(0,439) \\
\end{array}$ & $\begin{array}{c}3,846 \\
(2,193)\end{array}$ & $\begin{array}{c}2,308 \\
(1,797)\end{array}$ & $\begin{array}{c}4,923 \\
(1,754)\end{array}$ & $\begin{array}{c}6,538 \\
(0,776) \\
\end{array}$ & $\begin{array}{c}2,385 \\
(1,502)\end{array}$ & $\begin{array}{c}4,846 \\
(1,994)\end{array}$ & Only optical sensors \\
\hline 2 & High autonomy & $\begin{array}{c}2,273 \\
(1,191)\end{array}$ & $\begin{array}{c}2,545 \\
(0,934)\end{array}$ & $\begin{array}{c}5,636 \\
(1,286)\end{array}$ & $\begin{array}{c}4,000 \\
(2,191)\end{array}$ & $\begin{array}{c}4,364 \\
(1,912)\end{array}$ & $\begin{array}{c}2,818 \\
(1,537)\end{array}$ & $\begin{array}{c}6,455 \\
(0,934)\end{array}$ & $\begin{array}{c}, 182 \\
(1,662)\end{array}$ & $\begin{array}{c}1,091 \\
(0,302)\end{array}$ & Low autonomy \\
\hline 3 & High resolution & $\begin{array}{c}1,900 \\
(0,876) \\
\end{array}$ & $\begin{array}{c}2,900 \\
(1,449) \\
\end{array}$ & $\begin{array}{c}3,800 \\
(2,251) \\
\end{array}$ & $\begin{array}{c}4,200 \\
(1,476)\end{array}$ & $\begin{array}{c}3,400 \\
(1,174) \\
\end{array}$ & $\begin{array}{c}4,500 \\
(1,080) \\
\end{array}$ & $\begin{array}{c}5,300 \\
(1,829) \\
\end{array}$ & $\begin{array}{c}2,100 \\
(0,568) \\
\end{array}$ & $\begin{array}{c}5,600 \\
(1,350) \\
\end{array}$ & Low resolution \\
\hline 4 & High flight time & $\begin{array}{c}4,111 \\
(1,364)\end{array}$ & $\begin{array}{c}2,222 \\
(1,394)\end{array}$ & $\begin{array}{c}5,222 \\
(1,302) \\
\end{array}$ & $\begin{array}{c}2,222 \\
(0,667)\end{array}$ & $\begin{array}{c}2,222 \\
(1,716) \\
\end{array}$ & $\begin{array}{c}2,222 \\
(1,302)\end{array}$ & $\begin{array}{r}6,222 \\
(0,667) \\
\end{array}$ & $\begin{array}{c}1,556 \\
(0,726) \\
\end{array}$ & $\begin{array}{c}1,556 \\
(1,667) \\
\end{array}$ & Low flight time \\
\hline 5 & High safety requirements & $\begin{array}{c}3,375 \\
(1,302)\end{array}$ & $\begin{array}{c}5,625 \\
(1,302)\end{array}$ & $\begin{array}{c}4,500 \\
(2,070)\end{array}$ & $\begin{array}{c}1,250 \\
(0,463)\end{array}$ & $\begin{array}{c}1,625 \\
(1,408)\end{array}$ & $\begin{array}{c}2,000 \\
(0,535)\end{array}$ & $\begin{array}{c}5,875 \\
(0,991)\end{array}$ & $\begin{array}{c}2,000 \\
(1,604)\end{array}$ & $\begin{array}{c}1,875 \\
(1,727)\end{array}$ & Low safety requirements \\
\hline
\end{tabular}

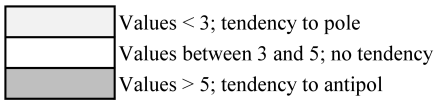

Out of the person-specific evaluations the aggregated construct classes were determined. The mean values of these evaluations determine the aggregated Full-Grid. An extract is shown in Table 3. The most frequently mentioned construct classes with the mean values of the person-specific evaluations and the standard deviations per mean value in brackets are shown.

\section{Evaluation of the aggregated full-grid}

Table 3 furthermore shows the tendency of each user group to the poles of the construct classes. For example, it is easy to realize that in the user group 'Marketing and Media' there are the special requirements for civil drone use of 'Only optical sensors', 'Low autonomy' and 'Low flight time'.

The mean values of the overindividual (aggregated) Full-Grid are also visualized in Fig. 3 for the three most mentioned user groups as characteristic profiles. The tendencies to the poles and overlays of the user groups regarding to their requirements for civil drones are clearly visible here.

Another graphical visualization is shown in Fig. 4. The mean values for each user group for the two most mentioned construct classes 'Special vs. only optical sensors' and 'High vs. low autonomy' are visualized. For example, it can be seen that the user groups 'Marketing and Media' and 'Private users' have a very low requirement of 'autonomy' and 'only optical sensors'. On contrary, the requirements for 'Energy Producers and Critical Infrastructure' are a 'High autonomy' and 'Special sensors'.

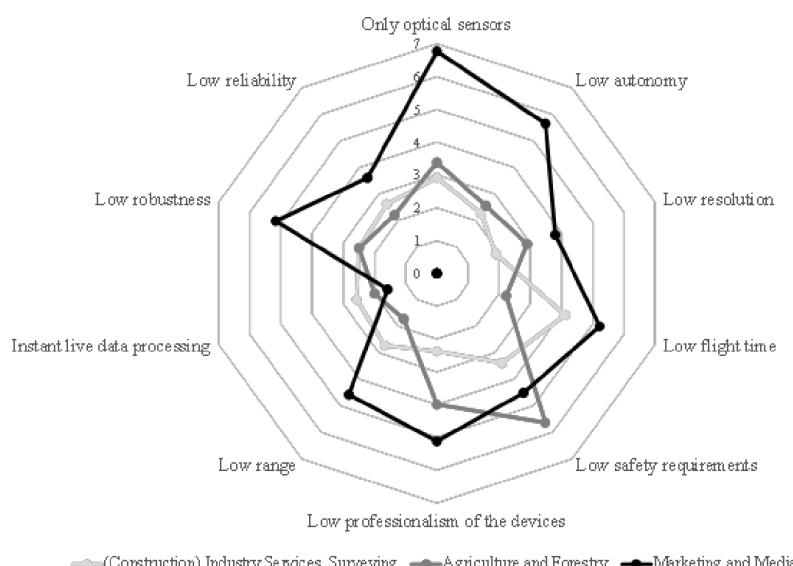

- (Corstruction) Industry Se rices, Surveying $\rightarrow$ - Agriculture and Fonestry $\rightarrow$ - Marketing and Media

Fig. 3. Visualization of the mean values for the three most mentioned user groups.

Special vs. only optical sensors (black) High vs. low autonomy (grey)

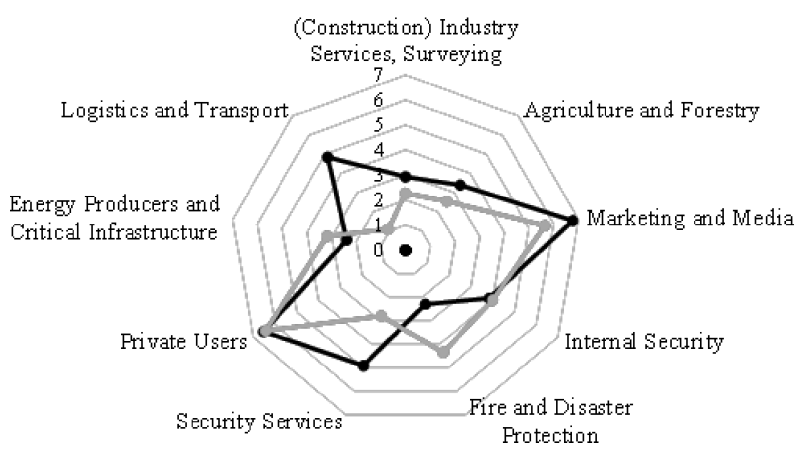

Fig. 4. Visualization of the mean values for the two most mentioned construct classes.

The results of this repertory grid survey serve as a basis for further interpretations. The frequencies of the elements give a first indication of the future im- 
portant user groups of civil drones. The evaluation of the elements per construct class light on the importance of certain requirements for civil drones in the user group. Behind each formed construct class, different technical requirements are hided, which may differ significantly again depending on the user group and the application ('High safety requirements' may refer, for example, to the redundancy of systems or the IP-protection class). This demands an accurate view per user group and application.

The results of the aggregated Full-Grid, in combination with current market forecasts could enable further valuable information for manufacturers and researchers in terms of future development needs with high market success. The 'Agriculture and Forestry' is a user group with adjusted high market success (see, e.g., [23]). In combination with the technology profiles determined by this repertory grid survey it is possible to adjudge that manufacturer

- that mainly have customers from 'Agriculture and Forestry' - should invest especially in the development of efficient engines and powerful batteries ('Long range' and 'High flight time'). However, advancements in data transfer can be neglect because no 'Immediate live data processing' is required. Furthermore, the expansion of the customer base to the user group '(Construction) Industry and Surveying' is to examine because there are mostly similar requirements for civil drones.

Also for regulators in authorities and the legislation itself, implications for future needs arise in the growing market of civil drones. For example, almost all user groups have strong requirements for 'High autonomy' and 'High safety requirements' for civil drones.

\section{Advantages and disadvantages of the repertory grid method}

The presented two-stage repertory grid method is a suitable alternative to exploratory methods such as the Delphi method and extends them by quantitative evaluations. Here, the main advantage is that construct systems - that have to be evaluated by the experts - are not named by the survey organizer rather by various experts. The clear structure of this method allows a goal-oriented approach and minimized - through the development of a common terminology - misunderstandings during the interviews. An upstream consultation with technical experts in terms of the considered innovation field to specify the element types (here the expert brainstorming) is however advisable to ensure a common understanding of the questionnaires by the subjects. The achievement of overindividual comparable levels of abstraction is also promoted by using the laddering technique in the interviews.

However, the repertory grid method also shows some weaknesses. So generally, the determination of classes for elements and constructs results an information loss. As work continues in the featured two-staged method, using only the most named elements and construct classes, also the risk exists that special innovative and important constructs and elements are not considered. For example, the construct of 'Detectability' of civil drones - which was only named twice in the presented survey - is currently hotly debated in the media and an essential element in the - outstanding - determination of a complete legal framework for the use of civil drones. However, an additional specification of the constructs by the interviewer is inadvisable because in this case the creative and knowledge-generating triad comparison and the method itself would be reduced to a semantic differential.

Furthermore, the high demands on the interviewer can be considered as a negative point of the repertory grid method. Especially when applying the laddering technique, the quality of the results depends largely on the interview management.

A final criticism of the presented investigation is certainly the highly complex innovation field of civil drones. The diverse application areas have - also in differentiation according to user groups - a considerable room for interpretation and thus are responsible for different evaluations of the requirements by the expert subjects.

\section{Conclusion: the repertory grid method as a basis for technology forecasting and preference measurement}

Especially in view of the systematic development of a common terminology and obtaining concrete data the advantages of the repertory grid method for technology forecasting - like it was used by Baier and Kohler [5] - and preference measurement are visible.

The presented investigation considered for technology forecasting in civil drones on one hand the main user groups and on the other hand their respective key requirements. Since subjects were surveyed along the entire innovation chain results are available on a broad basis and combine different perspectives.

For preference measurement the presented investigation could be a first step of surveying relevant features and attributes as an alternative for (e.g.) the elicitation technique (see e.g., [24]). Finally the last evaluations step of the presented survey is a sim- 
ple preference measurement and indicates results for feature preferences (here construct classes) of each user group.

Further research like a preference measurement focused on civil drones could be based on this investigation.

\section{References}

[1] Cuhls K., Grupp H., Blind K. [Eds.], Delphi '98 New Chances by Strategic Foresight [in Germany: Delphi '98 - Neue Chancen durch strategische Vorausschau], Karlsruhe: Fraunhofer-Institut für Systemtechnik und Innovationsforschung, 1998.

[2] Green K.C., Armstrong J.S., Graefe A., Methods to elicit forecasts from groups: Delphi and prediction markets compared, Foresight: The International Journal of Applied Forecasting, no. 8, 17-20, 2007.

[3] Armstrong J.S., Green K.C., Green H., Green C., Select a Forecasting Method (Selection Tree), Retrieved from http://forecastingprinciples.com/ index.php/selection-tree, 2015.

[4] ISI, Delphi '98 Survey: Study of Global Development of Science and Technology [in Grmany: Delphi '98 Umfrage - Studie zur globalen Entwicklung von Wissenschaft und Technik], Karlsruhe: Fraunhofer-Institut für Systemtechnik und Innovationsforschung, 1998.

[5] Baier D., Kohler T., Technology Foresight by Repertory Grid Method: Methodology and Practical Example [in Germany: Technikvorausschau mittels Repertory-Grid-Verfahren: Methodik und Praxisbeispiel], [in:] Möhrle M.G., Isenmann R. [Eds.], Technologie-Roadmapping: Zukunftsstrategien für Technologieunternehmen, pp. 177-192, Heidelberg: Springer, 2002.

[6] Reynolds T.J., Gutman J. Laddering: Extending the Repertory Grid Methodology to Construct Attribute-Consequence-Value Hierarchies, [in:] Pitts R.E. [Ed.], Personal Values and Consumer Psychology, pp. 155-167, A.G. Woodside. Lexington: D.C. Heath and Company, 1984.

[7] Sattler H., Methods for Measuring of Preferences of Innovations [in Germany: Methoden zur Messung von Präferenzen für Innovationen], Zeitschrift für betriebswirtschaftliche Forschung, 54, 6, 154-176, 2006 .

[8] Eckert J., Schaaf R., Methods for Preference Measurement - An Overview and Evaluation of existing and possible new Self-Explicated-Methods [in Germany: Verfahren zur Präferenzmessung Eine Übersicht und Beurteilung existierender und möglicher neuer Self-Explicated-Verfahren], Journal für Betriebswirtschaft, 59, 1, 31-56, 2009.
[9] Baumert K., Baier D., Brusch M., Identifying and Evaluating Characteristics that are Difficult to Quantify Using the Repertory Grid Technique, Proceedings of the 14th QMOD Conference on Quality and Service Sciences, pp. 225-231, San Sebastian, Spain, 2011.

[10] Armstrong J.S., The Seer-Sucker Theory: The Value of Experts in Forecasting, Technology Review, 83, June/July, 18-24, 1980.

[11] Häder M., Häder S., Recent Developments at DelphiMethod - Literature Review II [in Germany: Neuere Entwicklungen bei der Delphi-Methode - Literaturbericht II], Arbeitsbericht 98/05, Mannheim: ZUMA, 1998.

[12] Cuhls K., Technology Foresight in Japan: A Review of 30 Years Delphi Surveys [in Germany: Technikvorausschau in Japan: Ein Rückblick auf 30 Jahre Delphi-Befragungen], Heidelberg: Physica, 1998.

[13] Kelly G.A., The Psychology of Personal Constructs, New York: Norton, 1955.

[14] Catina A., Schmitt G.M., The Theory of Personal Constructs [in Germany: Die Theorie der Persönlichen Konstrukte], [in:] Scheer J.W., Catina A. [Eds.], Einführung in die Repertory GridTechnik. Bd. 1: Grundlagen und Methoden, pp. 1123, Bern: Hans Huber, 1993.

[15] Scheer J.W., Catina A., Psychology of Personal Constructs and Repertory Grid Technique [in Germany: Psychologie der Persönlichen Konstrukte und Repertory Grid-Technik], [in:] Scheer J.W., Catina A. [Eds.], Einführung in die Repertory GridTechnik. Bd. 1: Grundlagen und Methoden, pp. 810, Bern: Hans Huber, 1993.

[16] Stewart V., Stewart A., Business Applications of Repertory Grid, London: McGraw-Hill, 1997.

[17] Scheer J.W., Planning and Implementing of Repertory Grid-Surveys [in Germany: Planung und Durchführung von Repertory GridUntersuchungen], [in:] Scheer J.W., Catina A. [Eds.], Einführung in die Repertory Grid-Technik. Bd. 1: Grundlagen und Methoden, pp. 24-40, Bern: Hans Huber, 1993.

[18] Tan F.B., Hunter M.G., The repertory grid technique: a method for the study of cognition in Information Systems, MIS Quartely, 26, 1, 39-57, 2002.

[19] Curtis A.M., Wells T.M., Higbee T., Lowry P.B., An Overview and Tutorial of the Repertory Grid Technique, Information Systems Research, Communications of the Association for Information Systems (CAIS), 23, 3, 37-62, 2008.

[20] Fransella F., Bell R.C., Bannister D., A Manual for Repertory Grid Technique, 2nd ed, Chichester: John Wiley \& Sons, 2004. 
[21] Marsden D., Littler D., Repertory Grid Technique: An Interpretive Research Framework, European Journal of Marketing, 34, 7, 816-834, 2000.

[22] Green K.C., Armstrong J.S., Simple versus complex forecasting: the evidence, Journal of Business Research, 68, 8, 16783-1685, August 2015.

[23] Inea Consulting Ltd., World Commercial and Civil UAV Market Report 2015-2025. Retrieved from http://renewablemarketwatch.com/country-re ports/uav-drones/world-commercial-and-civil-uav- market-report-2015-2025-enterprise-unlimitedusers-detail, 2015.

[24] Reiners W., Multiattributive Preferencemodelling through Conjoint Analysis: Discussion of Processing Possibilities and Optimization of Pairwise Comparison Tasks at the Adaptive Conjoint Analysis [in Germany: Multiattributive Präferenzstrukturmodellierung durch die Conjoint Analyse: Diskussion der Verfahrensmöglichkeiten und Optimierung von Paarvergleichsaufgaben bei der adaptiven Conjoint Analyse], Münster: Lit Verlag, 1996. 